\title{
METHOD OF OBSERVATION AND THEIR EFFECTS IN THE SELECTION OF POTENTIAL FOOTBALL GOALKEEPERS
}

\section{Zerf Mohammed, Besultan Hadje, Attouti Norddine, Touati Blidi, Mokkedes Moulay Idriss}

Physical and Sports Education Institute Mostaganem, Sports Training Department Laboratory OPAPS, University Abdel Hamid Ibn Badis Mostaganem, 27000 Algeria.

\begin{abstract}
The criteria and methods for goalkeeper selection are more strict and complex than those of field players. Founded on its principles, the present study tried to examine the strengths and weaknesses of selection process practised by Algerian coaches. Interpret by Algerian scientists in their subjectivity in evaluating the amount of body fat and its effect on physical performance. Seen it's built with the naked eye. Confirmed by FIFA in two categories normal vs overweight, they should work harder under these conditions. For this proposal, eight teams from the leagues of Oran, Algeria Championship second division were involved in the study. Their goalkeepers were classified into the following groups: total $(\mathrm{GK}=28)$, Main goalkeeper $(\mathrm{MG}=14)$ and replacement goalkeeper $(R G=14)$.Tested at the end of the outward phase by penalty kicks test, ' $T$ ' Drill Test, Ruler Drop Test (TR) and anthropometric parameters (BH, BMI, BFP, BW). Backed on the applied statistical where our total sample is categorised in overweight, as well as no statistically significant differences between the two groups in all the comparisons practised. Our results confirm the weaknesses of traditional methods. Admit by similar studies in their subjective in evaluating the amount of body fat and its effect on physical performance correlate to anthropometric measurement.
\end{abstract}

Keywords: observation method, selection procedure, potential goalkeeper, Algerian soccer game.

DOI 10.1515/afepuc-2017-0014

(C) Acta Facultatis Educationis Physicae Universitatis Comenianae 


\section{Introduction}

The goalkeeper (GK) is at $80 \%$ of his team responsibility ranking (Smith 2008) success (Kacic 2015). Despite the fact that GK is the team's last line of defence and the first line of offence. Grant him or her the privilege to handgrip the ball (Dosil 2006) as a particular player to keep the ball (Buckland 2005) from travelling over the goal line using different skills than a field player as a separate class (Srebro \& Petcov 2002). Where these conditions, offer him or her the opportunity to be a strategist (Mulqueen 2010) during a match, reinforced by (Hurley 2011).

View the new laws obligatory by FIFA (MacKay 2015), which forbids the GK to keep the ball with both hands concurrently, and allows him or her to participate in the game as an eleventh player. Requiring from this last an additional fitness, that depends on several factors such as genetic traits, health, diet, environment, training schedule, moods and body composition (Ramos-Campo, Martinéz-Sánchez, Esteban-Garcia, Rubio-Arias, Bores, Clemente-Suarez \& Jiménez-Diaz 2014). Show by Milanovic et al. (2011) as physiological supplies located in the high intensity, indicators of physical performance (Krustrup, Mohr, Ellingsgaard \& Bangsbo 2005) associated with healthy body weight allied with fat percentage and body composition. Described in similar as an ultimate factor upsetting the physiological and morphological characteristics of performers. Deduced by Vincent et al. (2012) in the relation player's organisms and the levels of biological vitality relative to the achievement of physical loads. Which requires from the coaches the potential accurately inform around position-specific demands on their players and to drive the development of training practices that reflect the changing demands of the game (Gray \& Jenkins 2010)? The proof that explains the complications of criteria and the methods for selecting the goalkeeper, those are more complex than those of field players (Kacic 2007). The case of this study which supports its proposed protocol to examine the relationship between performance characteristics and selection processes, used by our goalkeeper coach, as a tool to identify gaps of the observation method as a selection procedure in the performance. Founded on the differences between our selected goalkeepers (MF versus RG).

From the background quoted by our scientists, that the national football never reached, its cruising speed, as much as the traditional method is used as selection means in football Algeria. Approve by Zerf (2016), the case of body fat cannot be stabilised by the naked eye. Revoked by the statistics of FIFA among overweight goalkeeper (Cantor \& Konin 2006) that they are called to work (Kindall \& Winkin 2000) harder under these conditions (Welsh 2014). Admit by similar in anthropometric parameters that enhance the physical performance, as well as the limitations of traditional methods put our coaches at risk for injuries in selecting the Algerian goalkeepers.

Founded on its principles, the present study attempted to examine the strengths and weaknesses of observation method practised by Algerian coaches to select their goalkeepers. Although our hypotheses sustain the literature review, which acknowledged the usefulness of analysis 
qualitatively or quantitatively from football demands. Where quantitative values give an overall trend, though qualitative values suggest specific training for occupying positions. Mentioned in similar studies as guidelines in establishing the individualised training and evaluation program in the players' career plan (Hamzaoui, Zerf, Messalti \& Abdelatif 2016).

\section{Methods}

The researchers used the descriptive approach with two groups of goalkeepers classified into the following groups: Total $(\mathrm{GK}=28)$, Main goalkeeper $(\mathrm{MG}=14)$ and Replacement goalkeeper $(\mathrm{RG}=14)$.

Represents all goalkeepers under 17 years with the best ranking in Oran football league during the 2015-2016 years. The second division holds in their posts their homogeneity is calculated based on age training and Test penalty kicks skill, reaction time (Ruler Drop Test), agility-T Test, and anthropometric parameters (body height, body mass, body mass index, body percent) at the end of the outward phase used in the current study (Table 1).

\section{Anthropometry, Body Composition, and percent of body fat}

Body height $(\mathrm{cm})$ and body mass $(\mathrm{kg})$ of each player were measured and the body mass index (BMI) was calculated $\left(\mathrm{kg} \cdot \mathrm{m}^{-2}\right)$, body fat percent based on Adult Body Fat $\%=(1.20 \mathrm{x}$ BMI $)+(0.23$ $\mathrm{x}$ Age $)-(10.8 \mathrm{x}$ gender $)-5.4$ using gender male $=1$, female $=0$. To evaluate the results: we refer to the normative data of BMI by the World Health Organization according to Brown et al. (2006). For BFP, we agree on the normative data provided by the Medical Science (Goswamy 2014).

\section{Ruler Drop Test (TR)}

The objective of this test is to monitor the athlete's reaction time. To undertake this test, we will require Metre ruler - Assistant, to conduct the test:

- The assistance between the outstretched index finger and thumb of the athlete's dominant hand holds the ruler so that the top of the athlete's thumb is level with the zero centimetre line on the ruler.

- The assistant releases the ruler and the athlete catches the ruler between their index finger and thumb as quickly possible.

- The assistant record distance between the bottom of the ruler and the top of the athlete's thumb, where the ruler has been caught.

- The test is repeated 2 more times and the average value used in the assessment.

To evaluate the results: we refer to the normative data, adapted by Davis (2000) for 16 to 19year (Davis 2000). 


\section{'T' Drill Test}

The subjects start from the standing point at cone A, and they are asked to run in a straight line to come to $\mathrm{B}$. Then, they slide to cone $\mathrm{C}$, which is the left side. After touching cone $\mathrm{C}$, they slide to the right and touch cone D. Finally, they run again to the left, touch Cone B, and run back to the start position. Every subject performed three trials with the best score recorded for analysis (Lockie, Schultz, Callaghan \& Jeffries 2014).

\section{Test penalty kicks skill}

In the penalty kick scenario, the goalkeeper is the threatening primary source in the environment (Martin 2015). While in the case of this study, we recruited 5 senior players who framed their shots well. Each goalkeeper must stop the 5 shots. All penalties go by the turn. The non-framed penalty it is not counted.

The results were analysed using SPSS software (version 20.0; SPSS, Inc., Chicago, IL). To assess the differences between the selected and non-selected players, the Student's t-test was performed using each variable. The results are described as mean and SD. The level of significance was established at $p<0.05$. Shapiro-Wilk and Levene's were conducted to calculate the normality and homogeneity. Although the correlation was calculated based on the Paired Samples Statistics (Table $1,2)$.

\section{Results}

The present study tried to examine the strengths and weaknesses of processes practised by Algerian coaches in the selection of goalkeepers. Based on the differences records between the selected goalkeepers (MG versus its replacement goalkeeper (RG)), as a protocol to predict the advantages and disadvantages of this method (Table 1). Built on applied statistics, our results show that our total sample is classified overweight, giving to their BMI, and acceptable, agreeing to their BFP. As well as the differences between the MG and RG are not statistically significant, account by the independent t-test. In all the comparisons practised. However, all person correlations are firmly positive between the two groups in the opposite of weight and height. Invoked by the search teams, to the effects of the same training, nephews of our championship and methods opted for MG. Interpret by Howley et al. (2017) that in general, body fatness negatively influences performance both mechanically and metabolically in most physical tasks that require translocation of body weight (Garrett, Donald \& Kirkendall 2000). Illustrated by Boron \& Boulpaep (2012). Thus, its upper, the movements become fluid and more energetically efficient, as exemplified by highly trained athletes. Claims in this study as defects of observation method, which bases its judgments on the behaviour of the naked eye. Recorded in body fat, as a parameter that influenced physical and anthropometric parameters (Zerf 2016). 
Table 1

Shows the normality and homogeneity of the total sample

\begin{tabular}{|c|c|c|c|c|c|c|c|}
\hline \multirow{4}{*}{ Weight } & & $\mathbf{N}$ & Mean \pm SD & \begin{tabular}{|l|} 
Shapiro-Wilk \\
\end{tabular} & $\mathbf{p} \leq \mathbf{0 , 0 5}$ & Levene's & $\mathrm{p} \leq \mathbf{0 , 0 5}$ \\
\hline & MG & 14 & $67,41 \pm 6,05$ & 0,949 & 0,538 & \multirow[t]{3}{*}{0,353} & \multirow[t]{3}{*}{0,558} \\
\hline & $\mathrm{RG}$ & 14 & $68,33 \pm 6,36$ & 0,894 & 0,094 & & \\
\hline & Total & 28 & $67,87 \pm 6,11$ & 0,944 & 0,472 & & \\
\hline \multirow[t]{3}{*}{ Height } & MG & 14 & $177,07 \pm 4,22$ & 0,935 & 0,358 & \multirow[t]{3}{*}{1,073} & \multirow[t]{3}{*}{0,310} \\
\hline & $\mathrm{RG}$ & 14 & $176,07 \pm 6,40$ & 0,912 & 0,168 & & \\
\hline & Total & 28 & $176,57 \pm 5,34$ & 0,908 & 0,148 & & \\
\hline \multirow[t]{3}{*}{$\overline{\mathrm{BFP}}$} & MG & 14 & $15,25 \pm 1,82$ & 0,943 & 0,458 & \multirow[t]{3}{*}{0,964} & \multirow[t]{3}{*}{0,335} \\
\hline & $\mathrm{RG}$ & 14 & $15,10 \pm 2,16$ & 0,945 & 0,482 & & \\
\hline & Total & 28 & $15,16 \pm 1,96$ & 0,889 & 0,078 & & \\
\hline \multirow[t]{3}{*}{ BMI } & MG & 14 & $25,16 \pm 1,71$ & 0,889 & 0,079 & \multirow[t]{3}{*}{2,27} & \multirow[t]{3}{*}{0,144} \\
\hline & $\mathrm{RG}$ & 14 & $25,61 \pm 1,39$ & 0,887 & 0,074 & & \\
\hline & Total & 28 & $25,89 \pm 1,56$ & 0,952 & 0,587 & & \\
\hline \multirow[t]{3}{*}{ Kicks } & MG & 14 & $1,6429 \pm 0,84$ & 0,941 & 0,427 & \multirow[t]{3}{*}{0,003} & \multirow[t]{3}{*}{0,955} \\
\hline & $\mathrm{RG}$ & 14 & $1,78 \pm 0,89$ & 0,944 & 0,467 & & \\
\hline & Total & 28 & $1,71 \pm 0,85$ & 0,949 & 0,538 & & \\
\hline \multirow[t]{3}{*}{ TR } & MG & 14 & $16,28 \pm 2,84$ & 0,894 & 0,094 & \multirow[t]{3}{*}{0,52} & \multirow[t]{3}{*}{0,477} \\
\hline & $\mathrm{RG}$ & 14 & $16,36 \pm 2,67$ & 0,944 & 0,472 & & \\
\hline & Total & 28 & $16,31 \pm 2,763$ & 0,935 & 0,358 & & \\
\hline \multirow[t]{3}{*}{ Agility } & MG & 14 & $10,26 \pm 0,66$ & 0,912 & 0,168 & \multirow[t]{3}{*}{0,361} & \multirow[t]{3}{*}{0,553} \\
\hline & $\mathrm{RG}$ & 14 & $10,71 \pm 0,59$ & 0,908 & 0,148 & & \\
\hline & Total & 28 & $10,48 \pm 0,65$ & 0,943 & 0,458 & & \\
\hline
\end{tabular}

Ratings for \% Body Fat Levels acceptable athletes $7-15 \%$, Body Mass Index (BMI) overweight $\geq 25$

Ruler Drop Test Average $15.9-20.4$ cm, 'T' Drill Test Average 10.13 - 10.37 s, penalty kicks skill Less goal

\section{Table 2}

Shows the comparison and the relationship between the two groups

\begin{tabular}{|c|c|c|c|c|c|c|}
\hline \multicolumn{3}{|c|}{$\mathbf{N}$} & $\mathbf{T}$ & $\mathbf{p} \leq \mathbf{0 , 0 5}$ & $\mathbf{R}$ & $\mathrm{p} \leq \mathbf{0 , 0 5}$ \\
\hline \multirow[t]{2}{*}{ Weight } & $\mathrm{MG}$ & 14 & \multirow[t]{2}{*}{$-0,39$} & \multirow[t]{2}{*}{0,699} & \multirow[t]{2}{*}{0,21} & \multirow[t]{2}{*}{0,47} \\
\hline & $\mathrm{RG}$ & 14 & & & & \\
\hline \multirow[t]{2}{*}{ Height } & $\mathrm{MG}$ & 14 & \multirow[t]{2}{*}{0,48} & \multirow[t]{2}{*}{0,630} & \multirow[t]{2}{*}{$-0,22$} & \multirow[t]{2}{*}{0,45} \\
\hline & RG & 14 & & & & \\
\hline \multirow[t]{2}{*}{$\mathrm{BFP}$} & $\mathrm{MG}$ & 14 & \multirow[t]{2}{*}{0,17} & \multirow[t]{2}{*}{0,867} & \multirow[t]{2}{*}{0,12} & \multirow[t]{2}{*}{0,69} \\
\hline & $\mathrm{RG}$ & 14 & & & & \\
\hline \multirow[t]{2}{*}{ BMI } & $\mathrm{MG}$ & 14 & \multirow[t]{2}{*}{0,94} & \multirow[t]{2}{*}{0,36} & \multirow[t]{2}{*}{0,14} & \multirow[t]{2}{*}{0,92} \\
\hline & $\mathrm{RG}$ & 14 & & & & \\
\hline \multirow[t]{2}{*}{ Kicks } & $\mathrm{MG}$ & 14 & \multirow[t]{2}{*}{$-0,44$} & \multirow[t]{2}{*}{0,67} & \multirow[t]{2}{*}{0,04} & \multirow[t]{2}{*}{0,96} \\
\hline & $\mathrm{RG}$ & 14 & & & & \\
\hline \multirow[t]{2}{*}{ TR } & $\mathrm{MG}$ & 14 & \multirow[t]{2}{*}{$-1,03$} & \multirow[t]{2}{*}{0,31} & \multirow[t]{2}{*}{0,19} & \multirow[t]{2}{*}{0,52} \\
\hline & RG & 14 & & & & \\
\hline \multirow[t]{2}{*}{ Agility } & $\mathrm{MG}$ & 14 & \multirow[t]{2}{*}{$\mid-1,87$} & \multirow[t]{2}{*}{0,07} & \multirow[t]{2}{*}{0,13} & \multirow[t]{2}{*}{0,68} \\
\hline & RG & 14 & & & & \\
\hline
\end{tabular}




\section{Discussion}

Hanging on the data collected in comparison with the normative data used in the present study. Where the independent $t$-test between the two groups in all the compares practised is insignificant. Our results claim defects of observation method base on coach naked eye. Confirmed by anthropometric studies, which suggested that certain physical factors, including body fat, body mass, muscle mass, and physique significantly influence athletic performance (Moncef, Said, Olfa \& Dagbaji 2012). The case of our selected goalkeepers (MG or RG) classified as overweight, according to BMI standards (Zerf, Noureddine \& Farouk 2017) as a factor influencing performance. Report by FIFA as unfavourable body weight gain, which requires additional work for the overweight goalkeeper. Deduced by the research team in the unified content of the sessions training goalkeepers among our soccer clubs. As much as the low level of our championship. Established by previous research the case of fatness as a phenomenon at risk factors injury related to the increase in body mass index (BMI), conducting the athlete to a multitude of other risk factors, which requires an examination of the association between overweight and sports damage (Ezzat, Schneeberg \& Koehoorn, 2014). Assumed by Kraemer et al. (2012) in their consequences on physical performance. Affirmed Brown et al. (2006), in the relation between body composition and advantage athletic performance to maintain a high level of fitness correlate to optimal athletic body competition. From the proof, that body composition analysis is part of the physical fitness assessment to esteem the gain of fat correlate to levels of lean muscle (Halfmann 2012) as expects global targets weight loss program (Fritz 2013) including the reduction of body fat (Griffin 2015) to achieve desired body composition. Our recommendations are directed to our fitness coach and especially for goalkeeper coaches to control and record the changes in body fat levels, appreciated by the influence of exercise training on physiological and performance changes related to weight loss as an assessment program (Kraemer, Fleck \& Deschenes 2012). The case of the current sample (MG or RG) experiencing in their increase in weight fatness, leading us to confirm, the sports involvement cannot guarantee physiological body mass and body composition, that requires from the coach/player to prescribe the exercise aimed at the body mass and the control of the facts (Nikolaidis 2012). Revealed by Peñas et al. (2014), that training programs among the soccer need to be modified considering its consequences on skill activities and athletic events; include agility, balance, coordination, power, reaction time and speed. Since they are closely related, with higher doses of physical activity leading to larger increases in physical fitness (Main \& Denehy 2015). As the primary goal of the training process is to stimulate the physiological, biomechanical, and psychological demands (Foran 2000). We highlight our overweight goalkeeper to work harder In order to develop them agility, speed, and flexibility, as well as willingness and motivation as a psychological procedure (Zimmerman \& England 2013). Moreover, to select the foremost goalkeeper, we accentuate our coaches' to look for desirable 
physical characteristics related to anthropometric parameters (Hargreaves 1990). Which is not the case of Algerian selectors and trainer, commented by the Algerian studies in the integration of goalkeeper in all training sessions (Hadjar, Koutchouk, Mime, Zerf \& Fateh 2016). As a complete conditioning program includes constant exercise (Di Iorio \& Ferretti 2004) to maintain or to improve their physical condition (Wein 1973) connected with them optional body competitive and its evaluation as a continuous process. Through previous theoretical data and background, we support the judgment quoted by our scientists, that the national football never reached, its cruising speed, as much as the traditional method is used as selection means in football Algeria. Evidence admits by Papaioannou et al. (2016) in the several problems when we use naked eye methods. Specified by Zerf et al. (2016) in its weakness to evaluate or to control the amount of Body Fat or fatness. Confirmed by Zahner (2012) in selection based on the "gaze of coach" which is subjective and based on instinct. On this basis, we suggested that the selection of players must be established founded on the positionspecific demands as well as field tests that may show the progress and gaps of our goalkeeper. Since physiological demands are associated with body composition change (body fat, bone and muscle) as a scientific basis in the codification of training programs, competent to improve physical performance in accordance with anthropometric levels. Advanced in the current study by official statistics establishes by FIFA via the overweight goalkeeper Cantor \& Konin 2006), which should work harder under these conditions to fulfil the specific physical requirements of their positions (Thissen \& Rollgen 2000). Whereas as a recommendation, we emphasise our trainers to apply the scientific method to evaluate the progress of their player with different aspects related to them position requirement (Kirkendall 2007).

\section{Conclusion}

It is essential that our coaches know the disadvantages and limitation of the method of observation in which their judgments are based on the view of a coach as a procedure for choosing their best goaltenders. Record in the present study in its failure to predict the effects of body composition (Thissen \& Rollgen 2000) on physical performance related to specified physical demands (Taverner 2005). Expressed by Reilly et al. (2000) to predict the success of talent in adult elite competition, the anthropometrical and physical characteristics are actually crucial to discriminate talented from non-talented soccer players (Robertson, Woods \& Gastin 2015). While in order to choose the potential goalkeepers, we recommend our coaches to approve their observations. On the basis of predisposing tests, consolidated with the qualities illustrated to evaluate. As much as to enhance their credibility and objectivity in selecting/detecting or evaluating the progression of their players in the long term or in the short term (Buchheit, Simpson, Al Haddat, Bourdon \& Villanueva 2012). Conflict of interest None. 


\section{Acknowledgments}

The authors would like to thank all the coaches and player involved in this study for their collaboration and unconditional support. Conflict of interests: None

\section{References}

1. BORON, W. F., \& E. L. BOULPAEP, 2012. Medical Physiology: A Cellular and Molecular Approach. Philadelphia: Saunders Elsevier.

2. BROWN, S. P., C. WAYNE MILLER \& J. M. EASON, 2006. Exercise Physiology: Basis of Human Movement in Health and Disease. Philadelphia: Lippincott Williams \& Wilkins.

3. BUCHHEIT, M., M. B. SIMPSON, H. AL HADDAD, P. C. BOURDON \& A. MENDEZVILLANUEVA, 2012. Monitoring Changes in Physical Performance with Heart Rate Measures in Young Soccer Players. Eur J Appl Physiol.112(2): 711-23.

4. BUCKLAND, M., 2005. Programming Game Ai by Example. UK: Jones \& Bartlett Learning.

5. CANTOR, E. \& J. G. KONIN, 2006. Body Mass Index For Fifa World Cup Professional Soccer Players. University Of South Florida Tampa: Florida US.

6. DAVIS B., 2000. Physical Education and the Study of Sport. 4th . Spain: Harcourt.

7. DI IORIO, L. \& F. FERRETTI, 2004. Goalkeeper Training Manual: Fundamental Drills to Improve Goalkeeping Technique. Spring City, Pa: Reedswain Publishing.

8. DOSIL, J., 2006. The Sport Psychologist's Handbook: A Guide for Sport-Specific Performance. US: Wiley.Com.

9. EZZAT, A., A. SCHNEEBERG \& M. KOEHOORN, 2014. Weighty problems: Sport Injuries in Overweight or Obese Active Canadian Adolescents.” Br j Sports Med. 48 : 592.

10. FORAN, B., 2000. High-Performance Sports Conditioning. Champaign, ILL: Human Kinetics, 2000.

11. FRITZ, S., 2013. Sports \& Exercise Massage: Comprehensive Care in Athletics, Fitness \& Rehabilitation. St. Louis, Mo: Elsevier Mosby.

12. GARRETT, W. E., T. DONALD \& T. KIRKENDALL, 2000. Exercise and Sport Science. Philadelphia: Lippincott Williams \& Wilkin.

13. GIPA, 2007. Water Polo Goalkeeper. Zagreb: Library of University Split.

14. GOSWAMY, N., 2014. The Medical Science of Total Body Transformation. US: Lulu Publishing Services.

15. GRAY A. J. \& D. G. JENKINS, 2010. Match Analysis and the Physiological Demands of Australian Football. Sports Med. 40(4): 347-60.

16. GRIFFIN. J. C., 2015. Client-Centered Exercise Prescription. Champaign, IL: Human Kinetics. 
17. HADJAR, K. H., S. M., KOUTCHOUK, M. MIME, M. ZERF \& Z. FATEH, 2016. Which Training Improves the Ability to Control and Manipulate the Ball Within the Goalkeeper in Football? European Journal of Physical Education and Sport Science. 1(4): 58-52.

18. HALFMANN, P., 2012. Advanced Concepts of Strength \& Conditioning for Tennis. Place of Publication not identified: Iaaph Gmbh.

19. HAMZAOUI, H., M. ZERF, L. MESSALTI \& H. ABDELATIF, 2016. Challenges and Constraints of Local Football from a Scientific Point of View. Revue Sciences et Pratiques des Activités Physiques Sportives et Artistiques. 10(2): 19-24.

20. HARGREAVES, A., 1990. Skills and Strategies for Coaching Soccer. Champaign, IL: Human Kinetics.

21. HOWLEY, E. T. \& D. L. THOMPSON, 2017. Fitness Professional's Handbook. Champaign, IL: Human Kinetics.

22. HURLEY, M., 2011. Goalkeeper. UK: Raintree.

23. KACIC, Z., 2015. Water Polo Goalkeeper. Split: Lulu.Com.

24. KINDALL, J. \& J. WINKIN, 2000. The Baseball Coaching Bible. US: Human Kinetics.

25. KIRKENDALL, D. T., 2007. Issues in Training the Female Player. Br J Sports Med. 41(Suppl 1): I64-I67.

26. KRAEMER, W. J., S. J. FLECK \& R. MICHAEL, 2012. Deschenes. Exercise Physiology: Integrating Theory and Application. Philadelphia: Wolters Kluwer/Lippincott Williams \& Wilkins Health.

27. KRUSTRUP, P., M. MOHR, H. ELLINGSGAARD \& J. BANGSBO, 2005. Physical Demands During An Elite Female Soccer Game: Importance Of Training Status. Medicine Science Sports Exercise. 37: 1242-8.

28. LAGO-PEÑAS, C., R. EZEQUIEL, L. CASÁIS \& M. GÓMEZ-LÓPEZ, 2014. Relationship Between Performance Characteristics and the Selection Process in Youth Soccer Players. J Hum Kinet. 27(40): 189-199.

29. LOCKIE, R. G., A. B. SCHULTZ, S. J. CALLAGHAN \& D. M. JEFFRIES, 2014. The Effects of Traditional and Enforced Stopping Speed and Agility Training on Multidirectional Speed and Athletic Function. Journal of Strength and Conditioning Research. 28(6): 1538-1551.

30. MACKAY, J., 2015. Notes of a Newsman: Witness to a Changing Scotland. US: Luath Press Ltd.

31. MAIN, E. \& L. DENEHY, 2015. Cardiorespiratory Physiotherapy: Formerly Physiotherapy for Respiratory and Cardiac Problems. Saintt Louis: Elsevier Health Sciences UK.

32. MARTIN, J., 2015. The Best of Soccer Journal: The Art of Coaching. Maidenhead: Aachen; HäGendorf; Vienna [U.A.]: Meyer \& Meyer Sport. 
33. MILANOVIC, Z., G. SPORIS \& N. TRAJKOVIC, 2011. Differences in Body Composite and Physical Match Performance in Female Soccer Players According to Team Position. 6th Inshs International Christmas Sport Scientific Conference. Szombathely, Hungary.

34. MONCEF CH., M. D. SAID, O. NAJLAOUI \& G. DAGBAJI, 2012. Influence of Morphological Characteristics on Physical and Physiological Performances of Tunisian Elite Male Handball Players. Asian J Sports Med. 3(2): 74-80.

35. MULQUEEN, T., 2010. The Complete Soccer Goalkeeper. US: Human Kinetics.

36. NIKOLAIDIS, P. T., 2012. Elevated Body Mass Index and Body Fat Percentage are Associated with Decreased Physical Fitness in Soccer Players Aged 12 - 14 Years. No. 3: 168-174.

37. RAMOS-CAMPO, D. J., F. MARTÍNEZ-SÁNCHEZ, P. ESTEBAN-GARCÍA, J. A. RUBIOARIAS, C. A. BORES, V. J. CLEMENTE-SUAREZ \& J. F. JIMÉNEZ-DIAZ, 2014. Body Composition Features in Different Playing Position of Professional Team Indoor Players: Basketball, Handball and Futsal. Int. J. Morphol. 32(4): 1316-1324.

38. REILly, T., A. M. WILliamS, A. NEVILL \& A. FRANKS, 2000. A Multidisciplinary Approach to Talent Identification in Soccer. J Sports Sci. 18(9): 695-702.

39. ROBERTSON, S., C. WOODS \& P. GASTIN, 2015. Predicting Higher Selection in Elite Junior Australian Rules Football: The Influence of Physical Performance and Anthropometric Attributes. J Sci Med Sport. 18(5): 601-6.

40. SMITH, S., 2006. Goalkeeping For Soccer. US: Coachwise $1^{\text {st }} 4$ sport.

41. SREBRO, R. \& V. PETCOV, 2002. Winning with Your Head: A Complete Mental Training Guide For Soccer. Spring City, Pa: Reedswain.

42. TAVERNER, C. M., 2005. Field Hockey Techniques \& Tactics. US: Human Kinetics.

43. THISSEN, G. \& K. ROLLGEN, 2000. Goalkeeping Drills. UK: Reedswain Inc.

44. VINCENT, T. L. \& J. S. BROWN, 2012. Evolutionary Game Theory, Natural Selection, and Darwinian Dynamics. Cambridge: University Press.

45. WEIN, H., 1973. The Science of Hockey. London: Pelham.

46. WELSH, A., 2014. The Soccer Goalkeeping Handbook. 3rd Edition. Bloomsbury: USA.

47. ZAHNER, L. E., 2012. The 12 Elements of the Success of the Swiss Olympic association for the Promotion of the Success. Swiss: Swiss Olympic.

48. ZERF M., A. NOUREDDINE \& B. F. ABDULLAH, 2017. Abdominal Obesity and their Association with Total Body: Fat Distribution and Composition. Case of Algerian Teenager Male High School Students. Physical Education of Students. 21(3): 146-151.

49. ZERF M., H. ABELATIF, M. MOKHTAR \& A. BENGOUA, 2016. Traditional Versus Scientific Method: The Differences Exist Between Selecting Players. Jpes 16 Supplement, No. 1: 673 - 678. 
50. ZERF, M., 2016. Impact of Percent Body Fat on Specific Ability - Algerian Soccer Players. SJSS 1: 16-23.

51. ZIMMERMAN, D. \& P. ENGLAND, 2013. Men's Lacrosse. Champaign, Il: Human Kinetic. 